\title{
The psychology of sustainability: factors and functional model for research
}

\author{
Vyacheslav Kazankov ${ }^{1, *}$ \\ ${ }^{1}$ St. Petersburg University of the State Fire Service EMERCOM of Russia, Ceo General of First \\ Legion LLC, 198206, St. Pionerstroya, 15/2, of.85, St. Petersburg, Russia
}

\begin{abstract}
Two hypotheses are presented in article. Hypothesis 1: The psychology of sustainability is person ability to retain health at the psychophysiological, psychological, and psychosocial levels of life under the influence of destroyers. As it appears from a hypothesis, we allocate three main a factor - psychophysiological, psychological, psychosocial. These factors form uniform model of a research of sustainability of the person. Two formulas by which it is possible to determine the general sustainability of the person and private sustainability are presented in article. Empirical data which can be interesting to much are provided in table 1. In it different age and social categories of the respondents choosing any given factor are presented. The hypothesis 2 represents the dynamic party of sustainability of the person. The dynamic side of sustainability is presented by three phenomena - it is process, this state, this property. These phenomena are peculiar to each factor of sustainability of the person. In the conclusion of article, it is indicated the separate direction in psychology «Psychology sustainability».
\end{abstract}

\section{Introduction}

A.Sisto, F.Vicinanza, L.L. Campanozzi, G. Ricci, D. Tartaglini and V. Tambone in work [1] write historical and cultural development of the concept resilience.

D. Fletcher and M. Sarkar in work [2] write that the a) specific nature of a definition is often influenced by the historical and sociocultural context within which the research was conducted, the researchers' conceptual proclivities, and the population sampled; b) one of the main difficulties in conducting research on resilience is that wide discrepancies exist in the way that resilience is defined and conceptualized, conceptual discrepancies hinder the evaluation and comparison of resilience research findings, preclude meta-analysis, and make it difficult to operationalize the construct for measurement purposes.

S.M. Southwick, G.A. Bonanno, A.S. Masten, C. Panter-Brick, R. Yehuda in work [3] write that determinants of resilience include a host of biological, psychological, social and cultural factors that interact with one another to determine how one responds to stressful experiences and resilience may change over time as a function of development and one's interaction with the environment.

\footnotetext{
${ }^{*}$ Corresponding author: kazankov-74@,mail.ru
} 
Relevance the psychology of sustainability (psychology of stability, psychology of resistance, psychology of resilience) it is reflected in articles of psychology [4].

A literature review of the term «psychological resilience» was performed by using the electronic databases «PubMed» and «PsycINFO». Scientific articles published between 2002 and May 2019 were. The search ultimately produced 126 definitions of psychological resilience developed by 109 work groups, and each of them has been catalogued by content and authors. Below is an overview of the key aspects of the following five macro-categories resilience:

- Ability to recover. Resilience has been defined as the ability to recover despite adverse conditions, looking ahead through a dynamic process of adaptation supported by a deeper knowledge of oneself and influenced by personal characteristics, family, and social resources.

- Type of functioning that characterizes the individual. Resilience is described in the literature as a peculiar response of the individual identified through the use of their personal characteristics to face difficult conditions.

- Capacity to bounce back. Resilience as capacity to bounce back outlines the ability to persist and grow when faced with stressors, to cope despite adversity, and to bounce from negative experience. Resilience refers to having good outcomes despite adversity and risk and could be described in terms of preserving the same level of outcome or rebounding back to that level after an initial setback.

- Dynamic process evolving over time. Resilience should therefore be understood not only as a personal attribute that can lead to success, but also as a dynamic interaction associated with adaptability and a positive history of functioning after adversities.

- Positive adaptation to life conditions. Resilience implies that emotional resources are used to adapt to adversity; therefore, it can also be described as the process that links resources (adaptive capacities) to results (adaptation).

V.V. Kazankov in work [5] write that based on stated we assumed that in a global sense sustainability is recommended to understand as a person able to maintain health - body, mental, and social under the influence of destroyers. Sustainability of a person is his ability to maintain health at the psychophysiological, psychological and psychosocial levels of life, forming in man a unity of the body, personality and subject of work in biotechnosociety the world of nature, technique, society. Destroyers are all that is aimed at damaging and (or) destroying the psychophysiological, psychological, or psychosocial health of a person.

Hypothesis 1: The psychology sense of sustainability is person ability to retain health at the psychophysiological, psychological, and psychosocial levels of life under the influence of destroyers.

Hypothesis 2: The psychology sense of sustainability a person as a process, as a condition, as a property at the psychophysiological, psychological and psychosocial levels.

\section{Materials and methods}

The validity of scale was studied over 10 years by comparing the results of respondents in a total sample of 1200 people, where 600 people used scale (experimental sample (ES)), another 600 people did not use it (control sample (CS)). Each sample consisted of such categories of respondents as graduate students - 150 people, 75 people in each sample; firefighters - 700 people, 350 in each sample; rescuers - 200 people, 100 in each sample; police officers - 150 people, 75 in each sample. The mean age was 31 years.

- Scientific research is conducted in three stages.

- $\quad$ Stage 1. Carried out the review of articles and reveal main units the psychology of sustainability (psychology of stability, psychology of resistance, psychology of resilience) at 
the psychophysiological level, psychological level and psychosocial level. We searched literature in PubMed, ELSEVIER, EBSCOHOST databases, google, and Google scholar. Articles are divided into two groups of searches. The first group included methods of research the following keywords to search for literature: the psychology of sustainability [6], psychology of stability [7], psychology of resistance [8], psychology of resilience [9]. «The current study provides evidence of the validity of self-assessed resilience among U.S. Army soldiers» [10]. «The concept of resilience has been defined as the capacity of individuals to cope with traumatic events» [11]. «Over the past decades, the concept of psychological resilience has stimulated a plethora of research in different fields including the psychological, medical and neurobiological sciences» [12]. «The evidence synthesized enriches debates on health system resilience by drawing on experiences from other sectors, so allowing for crosspollination of ideas» [13]. The second group included the review of information on the following keywords to search for literature: the psychology of sustainability [14], psychology of stability [15], psychology of resistance [16], psychology of resilience [17]. G.A. Bonnano and A.D. Mancini in work [18] write although the concept of resilience has gained in popularity over the course of this millennium, it has a somewhatlong history. Bruce S., Jason D. Gray, Carla Nasca in work [19] write resilience means to most people "achieving a positive outcomein the face of adversity". G.A. Bonanno and E.D. Diminich in work [20] write the term "resilience" has been in broad use for centuries, and over time has taken on a diverse assortment of meanings. It is only in the past several decades, however, that resilience has gained currency as a psychological construct.

- $\quad$ Stage 2. Created theoretical model the psychology of sustainability. The model was created based on the stage 1 analysis.

- Stage 3. Checked theoretical model the psychology of sustainability on respondents. Results of poll of 1200 respondents are presented to results at the first stages of research work:

- Results of a choice of a priority factor are presented in tables 1, 2. To each respondent three cards were given: 1) psychophysiological factor; 2) psychological factor; 3) psychosocial factor. It was offered to them: «To choose consistently a factor from important to less important».

- The following results are presented in table 3. It was offered to respondents: «1. Break down the execution of a conditional task into stages; 2. Give a name to each stage». Algorithm of a conditional task: an entrance to a situation - stay in a situation - getting out of the situation. Task: students - passing the exam; firefighters - extinguishing a fire; rescuers - rescuing the victim; police officers - detention of the criminal.

\section{Results}

Stages 1-2. We established keywords: in English concepts - the psychology of stability, psychology of resistance, psychology of resilience; in Russian the basic concept the psychology of sustainability $(\Omega)$.

The analysis of sources showed that all research take place in three main directions: psychophysiology, psychology and psychosociology. From a historical viewpoint, there are two major discourses of resilience - the physiological and psychological. The specific nature of a definition is often influenced by the historical and sociocultural context within which the research was conducted, the researchers' conceptual proclivities, and the population sampled. One obstacle to an adequate biopsychosocial model of resilience is the lack of well-validated measures of this construct. It only confirms our hypothesis 1: The psychology sense of sustainability is person ability to retain health at the psychophysiological, psychological, and psychosocial levels of life under the influence of destroyers. 
Psychophysiological level $(\varphi)$ is the registration of the physiological reactions of an individual when sustainability of a person is established by markers: cardiovascular system (blood pressure relative to normal); eye reactions and facial expressions; skin reactions (sweating), etc. Through the nervous system through feedback lines, physiological markers are interpreted by psychic markers: attention, expressed as a perception of information; thinking reflected in logic, decision-making, etc. $\Omega \varphi-$ is sustainability at the psychophysiological level. Psychophysiological level of the person reveals the activity of: 1) body and psyche; 2) nervous system - strength, mobility, poise; 3) cognitive mental processes - sensation, perception, memory, attention. Consequently, psychophysiological sustainability is the ability to maintain healthy performance at the psychophysiological level.

Psychological level $(\psi)$ is the registration of emotions and mental states of a person, when a human sustainability is established by markers: valency (tone) of emotions, their intensity (strength), activity and content, which forms emotional, activation, tonic and tensile mental states with their characteristic markers. $\Omega \psi-$ is sustainability 'at the psychological level. Psychological level of the person reveals the activity of: 1) mental processes - cognitive (representation, imagination, thinking, speech) and emotional (emotions, affects, feelings, mood, an emotional stress); 2) mental states - emotional, activation, tonic, tenzionny. Consequently, psychological sustainability is the ability to maintain healthy performance at the psychological level.

Psychosocial level (s) is registration of the volitional manifestation of the orientation of the labour subject, when human sustainability is registered with markers: the ability to consciously choose the actual demand, motive, with the subsequent delivery of the goal; the ability to own and control your own behaviour; the presence of a worldview and beliefs, united by the concepts of «life» and «activity». $\Omega \mathrm{s}-$ is sustainability at the psychosocial level. Psychosocial level of the person reveals the activity of: 1) volitional mental of processes; 2) internal and external motives and feeling; 3) character in relation to itself, people and work. Consequently, psychosocial sustainability is the ability to maintain healthy performance at the psychosocial level.

Psychophysiological, psychological and psychosocial levels allow to formulate factors model of psychology of sustainability (Fig. 1).

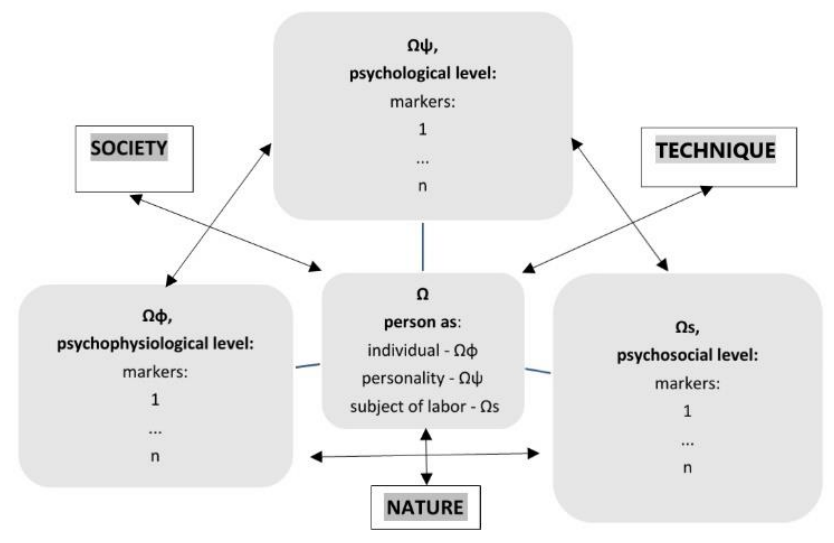

Fig. 1. Factors model of psychology of sustainability.

Our research showed that the psychology of sustainability should be considered as process, as a state, as property at the psychophysiological, psychological, and psychosocial levels. 
Person sustainability as a process: is the formation of the purpose, decision-making, adaptation, endurance, and permission at the psychophysiological, psychological and psychosocial levels.

Person sustainability as condition: is ready state, condition of activity, condition of satisfaction, condition of rest at the psychophysiological, psychological, and psychosocial levels.

Person sustainability as a property: selectivity, plasticity, variability, steadiness, resilience at the psychophysiological, psychological and psychosocial levels.

It only confirms our hypothesis 2 : The psychology sense of sustainability a person as a process, as a condition, as a property at the psychophysiological, psychological and psychosocial levels. From a hypothesis 2 implies a functional model of psychology of sustainability - the dynamic party of sustainability follows (Fig. 2).

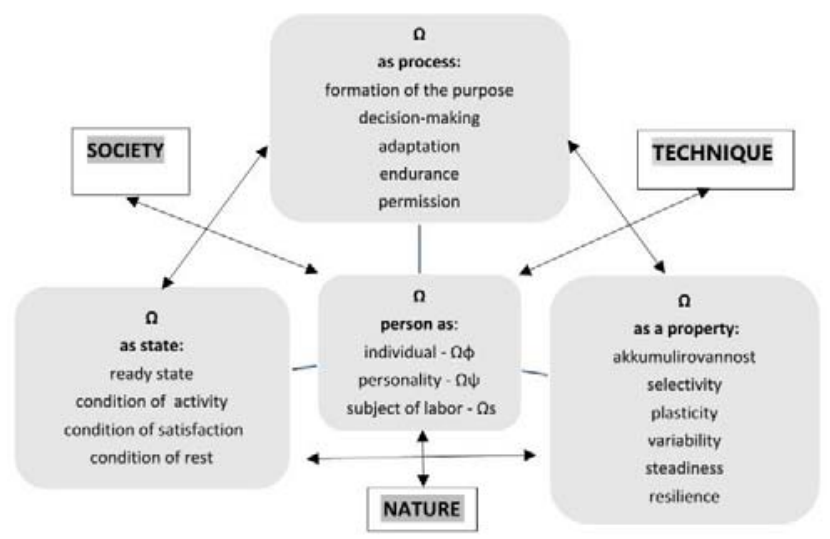

Fig. 2. Functional (dynamic) model of psychology of sustainability.

Stage 3. This section presents the experimental results, which are shown in tables 1-4 and associated with the hypotheses put forward.

Table 1 is based on interviews with respondents. The data in table 1 indicate the possibility of an intuitive assessment and of a choice of a priority factor by respondents the psychophysiological, psychological, and psychosocial.

Table 1. Priority factor.

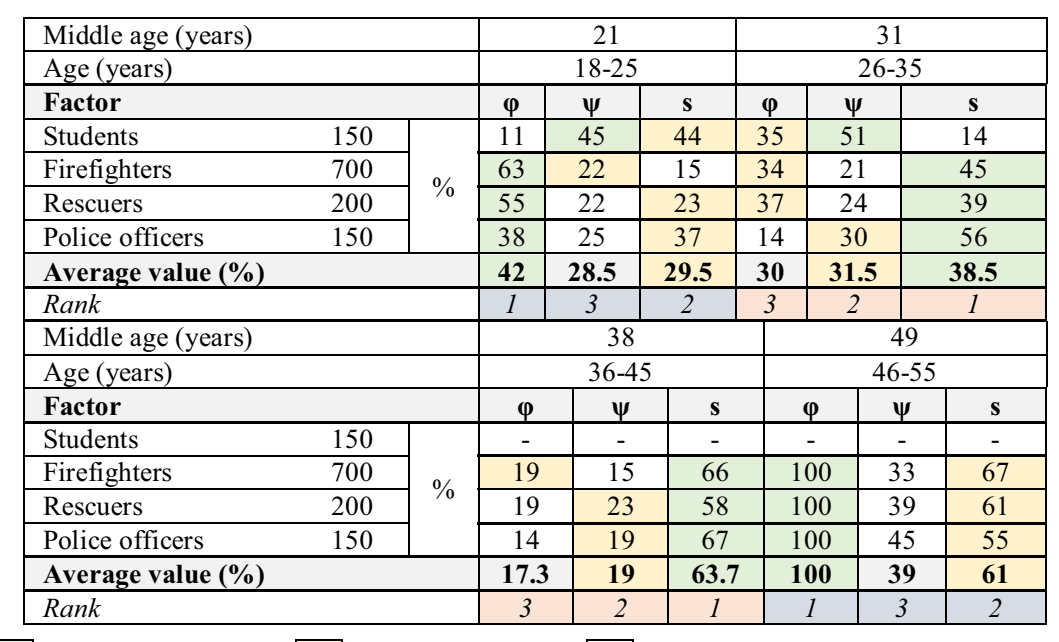

The greatest $\% \quad \square$ The average $\% \quad \square$ The smallest $\%$ 
The results of Table 2 indicate of a choice of a priority factor by respondents the psychophysiological, psychological, and psychosocial.

Table 2. Factors and associations.

\begin{tabular}{|l|c|c|}
\hline \multicolumn{1}{|c|}{ Factor } & Association & 1200 respondents (\%) \\
\hline Psychophysiological factor $(\varphi)$ & Body & 100 \\
\hline Psychological factor $(\psi)$ & Mental states & 73 \\
\hline \multirow{2}{*}{ Psychosocial factor $(\mathrm{s})$} & Living conditions & 67 \\
\cline { 2 - 3 } & Social status & 33 \\
\hline
\end{tabular}

The data in tables 3, 4 indicate show ability of respondents to divide process of performance of a task into stages and to characterize them.

Table 3. Short characteristic of stages.

\begin{tabular}{|c|c|c|c|}
\hline Respondents & $\begin{array}{l}\text { Quantity } \\
\text { of stages }\end{array}$ & $\begin{array}{c}\text { № of } \\
\text { stages }\end{array}$ & Short characteristic \\
\hline \multirow{3}{*}{ Students } & \multirow{3}{*}{3} & 1 & Obtaining the ticket $-\langle$ «set up» \\
\hline & & 2 & $\begin{array}{l}\text { The solution of the ticket and protection of the } \\
\text { answer - «tension and persistence» }\end{array}$ \\
\hline & & 3 & Receiving an assessment - «to shoot back» \\
\hline \multirow{3}{*}{ Firefighters } & \multirow{3}{*}{3} & 1 & $\begin{array}{l}\text { «Expeditious expectation» - readiness for } \\
\text { extreme work }\end{array}$ \\
\hline & & 2 & To make work \\
\hline & & 3 & To have satisfaction from the performed work \\
\hline \multirow{3}{*}{ Rescuers } & \multirow{3}{*}{3} & 1 & Readiness for extreme work \\
\hline & & 2 & To make work \\
\hline & & 3 & To have satisfaction from the performed work \\
\hline \multirow{3}{*}{$\begin{array}{l}\text { Police } \\
\text { officers }\end{array}$} & \multirow{3}{*}{3} & 1 & To be ready to detain the criminal \\
\hline & & 2 & To detain the criminal \\
\hline & & 3 & To have a rest after work \\
\hline
\end{tabular}

Table 4. Names of stages.

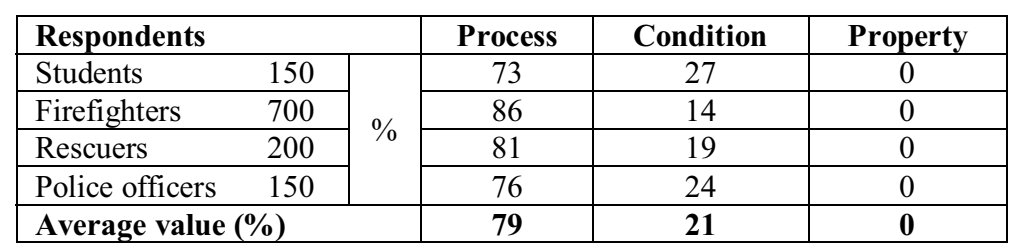




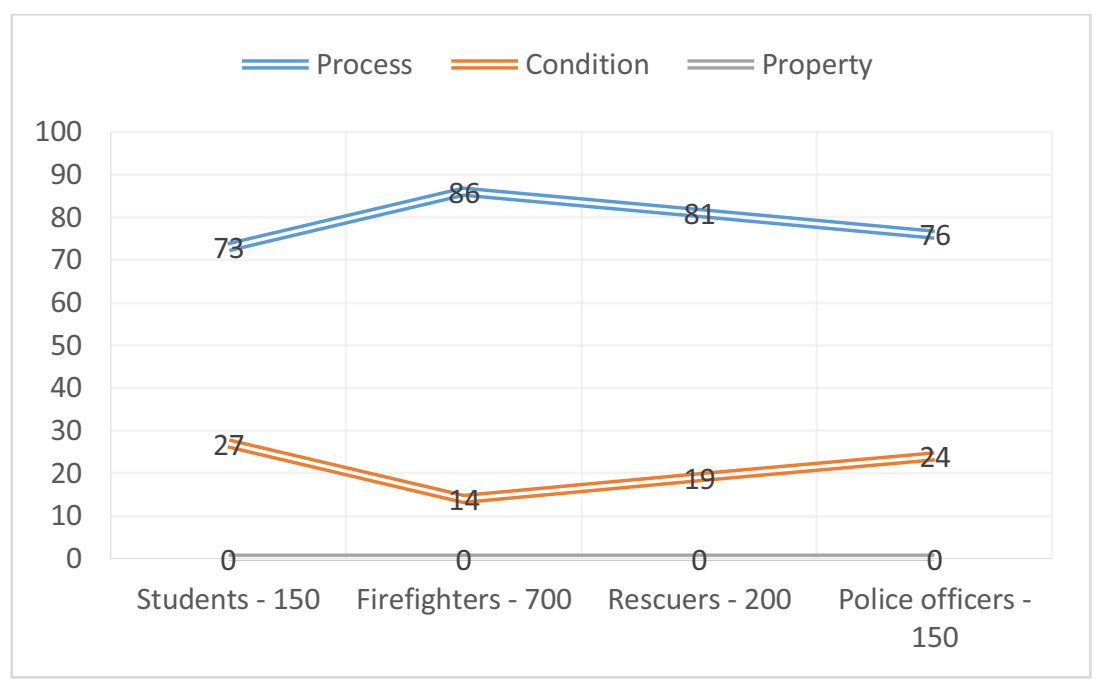

Fig. 3. Graphic interpretation of table 4.

\section{Discussion}

From this article follows that in psychology a phenomenon « sustainability » has something in common with the directions of research of the person: psychophysiological, psychological, and psychosocial. Psychophysiological level is the nervous system in determining the individual's mental activity. Psychological level is emotions that form the mental state of the individual. Psychosocial level is volitional manifestation of the orientation of the labor subject. These directions represent factors model of sustainability of the person (Fig. 1). Each factor has the markers of an assessment: psychophysiological sustainability, psychological sustainability, psychosocial sustainability. On markers of each factor the psychologist can establish the general sustainability of the person. The total sustainability of a person is measured in relative units (r.u.) and is determined by the formula (1):

$$
\Omega=\frac{\Omega \varphi+\Omega \psi+\Omega s}{n}(r . u .)
$$

Where,

$\Omega$ is total sustainability of a person (r.u.);

$\mathrm{n}$ is the number of sustainability levels, usually $=3$;

$\Omega \varphi$ is sustainability at the psychophysiological level (r.u.);

$\Omega \psi$ is sustainability at the psychological level (r.u.);

$\Omega$ s is sustainability at the psychosocial level (r.u.).

$\Omega \varphi, \Omega \psi$, and $\Omega$ s are calculated using the same formula (2):

$$
\Omega \varphi, \Omega \psi, \Omega s=\frac{\sum m}{n}(r . u .)
$$

Where,

$\mathrm{m}$ - is numerical values, equivalent markers for evaluating $\varphi, \psi$, s (r.u.) (in detail markers in article are not considered).

$\mathrm{n}$ - is the number of measured markers.

It follows from formula (2) that the more markers of each level are registered, the more objectively and informatively the numerical value of the total sustainability of a person is calculated. 
Psychophysiological sustainability, psychological sustainability, psychosocial sustainability are functionally connected among themselves by the mental phenomena (tables 3, 4; Fig.2). Dynamic party of functional model (Fig. 2) it is possible to illustrate (Fig. 4).

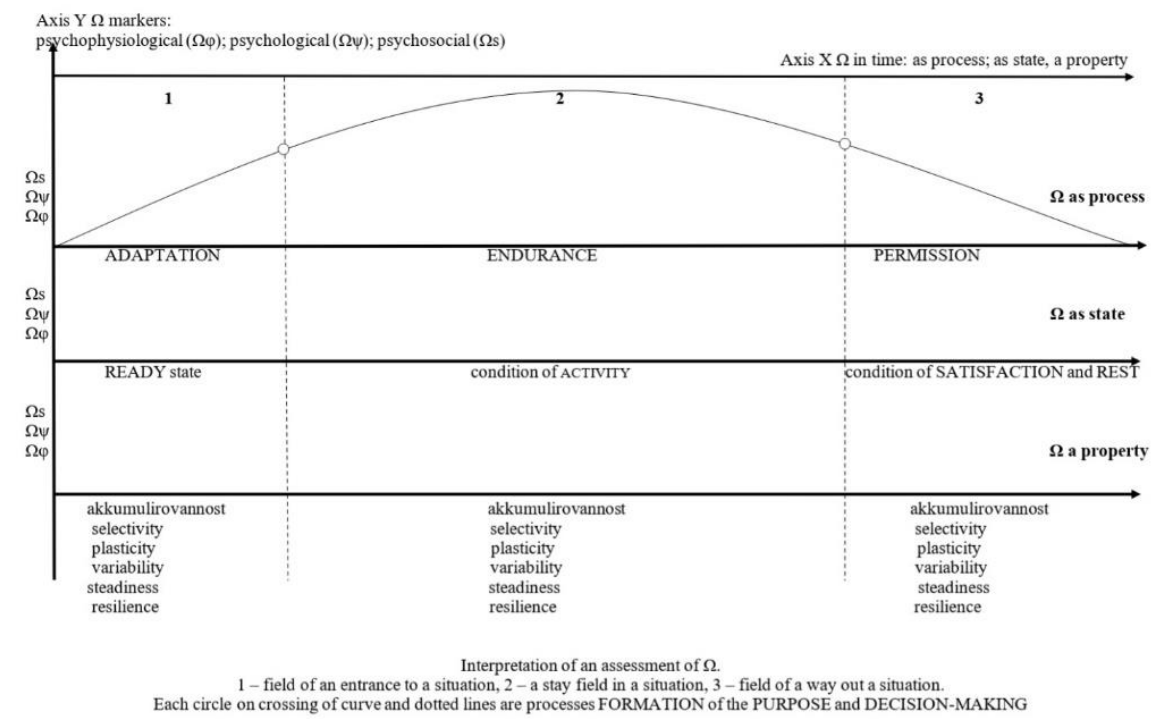

Fig. 4. The factors and functional model for research.

Fig. 4 shows dynamic communication of the factors model (Fig. 1) (it is postponed on an axis of factors - Y) and functional model (Fig. 2) (it is postponed on time axis - X). The axis of time shows sustainability as process, as a state, as property at three stages ( 1 - field of an entrance to a situation, 2 - a stay field in a situation, 3 - field of a way out a situation). The axis of factors shows stability on markers of a psychophysiological factor, a psychological factor, a psychosocial factor at three stages ( 1 - field of an entrance to a situation, 2 - a stay field in a situation, 3 - field of a way out a situation). Gauss's curve figuratively illustrates process of occurrence into a situation, stay in a situation, a way out. Fig. 3 illustrates these tables 3 and partially tables 4 .

It follows from Table 1 that respondents at an intuitive level understand the meaning of psychophysiological level, psychological level, psychosocial level. Follows from table 1 that respondents at the intuitive level understand value of psychophysiological level, psychological level, psychosocial level. Therefore, it is possible to work with them without any special preparation. Also data give the grounds a half-corduroy road that about three factors of stability and are possible to work with other category of people who need to be examined. To 25 and after 46 years the respondents connect stability with psychophysiological (1 rank) and psychosocial (the 2nd rank) factors, interpretation of such position is reflected in table 2 . Students connect the stability with a psychological factor (1 rank). From 26 to 45 years the psychosocial factor (1 rank) comes out on top that is connected with achievement of the social status in society and improvement of material living conditions of life.

\section{Conclusions}

In the conclusion we will note that the presented models define in psychology conceptual approach and research of sustainability of the person. The existing research belong to one of three offered factors (psychophysiological, psychological, psychosocial), or cover at the 
same time all three factors. The psychophysiological factor, psychological factor, psychosocial factor represents a whole in a research of sustainability of the person. Static and dynamic manifestations of the psychological phenomena are peculiar to them. therefore, it is necessary to speak about the new direction in psychology - «Psychology sustainability». The psychology sustainability is manifestation psychology of stability, psychology of resistance, psychology of resilience. «Psychology sustainability» is the psychology of the 21 st century developing the technologies estimates, formations and development of sustainability of the person to modern reality.

\section{References}

1. A. Sisto, F. Vicinanza, L.L. Campanozzi, G. Ricci, D. Tartaglini, V. Tambone, Towards a Transversal Definition of Psychological Resilience: A Literature Review. Medicina 55, 745 (2019), doi:10.3390/medicina55110745

2. D. Fletcher, M. Sarkar, Psychological resilience: A review and critique of definitions, concepts, and theory, Eur. Psych. 18(1), 12-23 (2013) doi: 10.1027/1016-9040/a000124

3. S.M. Southwick, G.A. Bonanno, A.S. Masten, C. Panter-Brick, R. Yehuda, Resilience definitions, theory, and challenges: interdisciplinary perspectives, European Journal of Psychotraumatology 5 (2014)

4. D. Jackson, A. Firtko, M. Edenborough, Personal resilience as a strategy for surviving and thriving in the face of workplace adversity: a literature review, Journal of Advanced Nursing 60(1), 1-9 (2007), doi: 10.1111/j.1365-2648.2007.04412.x

5. V.V. Kazankov, Scientific and technical statements of St. Petersburg State Polytechnic University. Society. Communication. Education 127-132 (2010) doi.org/10.24412/Ff8Fj8Jpmc8

6. V.V. Kazankov, Bulletin of the Leningrad State University 65-76 (2010) doi.org/10.24412/Ff8E8mTGxIU

7. M.A. Harris, C.E. Brett, Personality Stability From Age 14 to Age 77 Years, Psychology and Aging 31, 8, 862- 874 (2016) http://dx.doi.org/10.1037/pag0000133.supp

8. Y. Xie, L. Peng, X. Zuo, M. Li, The Psychometric Evaluation of the Connor-Davidson Resilience Scale Using a Chinese Military Sample, PLoS ONE 11(2) (2016) e0148843. doi:10.1371/journal. pone.0148843

9. W. Lei, Y. Tan, Y. Liu, Factor structure and psychometric evaluation of the ConnorDavidson resilience scale in a new employee population of China, BMC Psychiatry 17, 49 (2017) DOI 10.1186/s12888-017-1219-0

10. L. Campbell-Sills, M.B. Stein, J. Trauma, Stress 20(6), 1019-1028 (2007) doi.org/10.1002/jts. 20271

11. J. Scali, C. Gandubert, K. Ritchie, M. Soulier, M.-L. Ancelin, et al., Measuring Resilience in Adult Women Using the 10-Items Connor-Davidson Resilience Scale (CDRISC). Role of Trauma Exposure and Anxiety Disorders, PLoS ONE 7(6), e39879 (2012) doi:10.1371/journal.pone.0039879

12. A. Chmitorz, M. Wenzel, R.-D. Stieglitz, A. Kunzler, C. Bagusat, I. Helmreich, et al., Population-based validation of a German version of the Brief Resilience Scale, PLoS ONE 13(2), e0192761 (2018) https://doi.org/10.1371/journal. pone.0192761

13. E. Barasa, R. Mbau, L. Gilson, What is resilience and how can it be nurtured? A systematic review of empirical literature on organizational resilience, Int. J. Health. Policy Manag. 7(6), 491-503 (2018) doi:10.15171/ijhpm.2018.06 
14. V.V. Kazankov, O.V. Gumenyuk, Scientific and Technical Journal of St. Petersburg State Polytechnic University. Society. Communication. Education, 130-135 (2010) doi.org/10.24412/Ff8Gw_t4Q7k

15. M. Scheffer, J.E. Bolhuis, D. Borsboom, T.G. Buchman, et al., Quantifying resilience of humans and other animals, PNAS 115, 47 11883-11890 (2018) www.pnas.org/cgi/doi/10.1073/pnas.1810630115

16. S. Yasien, J.A. Nasir, T. Shaheen, Relationship between psychological distress and resilience in rescue workers, Saudi. Med. J. 37(7), 778-782 (2016) doi: 10.15537/smj.2016.7.15004

17. M. Pęciłło, The concept of resilience in OSH management: a review of approaches, Inter. J. of Occup. Saf. and Erg. 22:2, 291-300 (2016) DOI: 10.1080/10803548.2015.1126142

18. G.A. Bonnano, A.D. Mancini, Pediatrics 121, 369-375 (2008) doi: 10.1542/peds.20071648

19. S. Bruce, D.G. Jason, C. Nasca, Recognizing resilience: Learning from the effects of stress on the brain, Neurobiology of Stress. 1(1), 1-11 (2015)

20. G.A. Bonanno, E.D. Diminich, Annual Research Review: Positive adjustment to adversity - Trajectories of minimal-impact resilience and emergent resilience, J. Child. Psychol. Psychiatry 54(4), 378-401 (2013) doi:10.1111/jcpp.12021 